\title{
Determinants of Periodontal Disease in Pregnancy in an Urban Setting in Zimbabwe
}

\author{
Clara Haruzivishe1, Tafadzwa Ghandi², Shalote Chipamaunga3, Doreen Mukona1, \\ Judith Rukweza ${ }^{1}$ \\ ${ }^{1}$ Department of Nursing Science, College of Health Sciences, University of Zimbabwe, Harare, Zimbabwe \\ ${ }^{2}$ Department of Dentistry, College of Health Sciences, University of Zimbabwe, Harare, Zimbabwe \\ ${ }^{3}$ Department of Health Professional Education, College of Health Sciences, University of Zimbabwe, Harare, Zimbabwe \\ Email: schipamaunga8@gmail.com
}

How to cite this paper: Haruzivishe, C., Ghandi, T., Chipamaunga, S., Mukona, D. and Rukweza, J. (2019) Determinants of Periodontal Disease in Pregnancy in an Urban Setting in Zimbabwe. Open Access Library Journal, 6: e5418.

https://doi.org/10.4236/oalib.1105418

Received: April 22, 2019

Accepted: May 21, 2019

Published: May 24, 2019

Copyright () 2019 by author(s) and Open Access Library Inc.

This work is licensed under the Creative Commons Attribution International License (CC BY 4.0).

http://creativecommons.org/licenses/by/4.0/

\begin{abstract}
Periodontal disease is one of the most common infectious diseases in pregnancy. The disease is caused by bacteria that produce inflammation of gingiva through production of inflammatory mediators that may have direct insult on amnion. Untreated and chronic dental infections have a possibility of causing harm to both the mother and the baby. This was an analytical cross-sectional study the purpose of which was to determine the prevalence and risk factors for periodontal disease in pregnancy. The study was conducted on a random sample of 350 postnatal mothers at Harare city Primary Care clinics. Study approval was granted by the Joint Research Ethics Committee of the University of Zimbabwe, College of Health Sciences and Parirenyatwa Group of Hospitals (JREC), the Medical Research Council of Zimbabwe (MRCZ) and Harare City Directorate. All participants gave informed consent. Code numbers were used to identify participants and interviews and oral assessments were conducted in private rooms. Data was collected through face to face interviews following a structured questionnaire, clinical intraoral examination and from clinical records. Data was captured using research electronic data capturing (RedCap) and was analyzed using the Statistical Package for Social Sciences (SPSS). Mean maternal age was 25.9 years, SD 5.7. prevalence of periodontal disease was $48.7 \%$. No significant factors were associated with periodontal disease in the current study. However, other studies have reported significant risk factors for periodontal disease such as gestation age of the pregnancy and place of residence periodontal disease was significantly associated with the following birth outcomes. Periodontal health is the relatively neglected area in perinatal care. Health care professionals should be trained in screening for periodontal disease and giving health education in order to reduce adverse perinatal outcomes.
\end{abstract}




\section{Subject Areas}

Nursing

\section{Keywords}

Periodontal Disease, Pregnancy, Preterm Low-Birth

\section{Introduction}

Approximately $40 \%$ of pregnant women have some form of periodontal disease and the rate is higher among women of low socioeconomic status [1]. Periodontal diseases are bacterial infections that destroy the attachment fibres and supporting bones that hold the teeth and often result in severe breakdown of tooth supporting structures [2]. Tissues that are often involved in periodontal disease are gums which include gingiva, periodontal ligament, cementum and alveolar bone. Periodontal disease presents in different forms that include gingivitis (the mild and reversible form characterized by inflammation without tissue damage) and periodontitis (the more advanced and severe form characterised by attachment and bone loss) [3]. Though periodontal disease is a localized condition, it has potential to induce effects that have an influence on severe systemic conditions. Examples of associated adverse pregnancy are preterm birth, low birth weight, stillbirth, abortion, maternal and neonatal mortality are common adverse pregnancy outcomes [2].

The main cause of periodontal disease is bacterial plaque, a sticky, colorless film that consistently forms on teeth [4]. However, plaque can be effectively removed by daily brushing teeth with a toothbrush using fluoride toothpaste and by flossing [4]. Daily brushing with fluoride toothpaste also strengthens teeth and protects against decay. If not removed by daily brushing, plaque hardens to form tartar that can only be removed professionally by a dentist [5].

The same authors assert that in pregnancy hormonal changes that occur make gums more sensitive and make it easier for gingivitis to develop. Elevated progesterone hormone levels will stimulate production of prostaglandins which cause inflammation of blood vessels in the gum tissue [4]. It is very important that pregnant women receive oral health assessment and necessary care as oral health conditions may affect the pregnancy. The most common maternal oral diseases include dental caries, gingivitis, and periodontitis.

It is especially important to have a dental check-up, dental cleaning, and any necessary treatment during pregnancy. Delaying necessary treatment for oral health problems during pregnancy could result in significant risk to a mother and baby [6] [7]. The second trimester is a good time to schedule a routine visit to a dental professional, however, if a pregnant woman experiences a problem at any time during pregnancy, she is advised to seek professional help immediately [8]. 
The prevalence of periodontal disease is not known in Zimbabwe. Periodontal infections are common in pregnancy especially in people of low socio-economic status. Oral health education, assessment and treatment in pregnant women are lacking in primary care centres where majority of pregnant women are seen for ANC. The purpose of this study therefore was to determine the prevalence of periodontal disease in pregnancy together with associated risk factors.

\section{Methodology}

This was an analytical cross-sectional study. A random sample of 350 postnatal mothers was selected from Harare City Primary Care Centres. Study approval was granted by the Joint Research Ethics Committee of the University of Zimbabwe College of Health Sciences and Parirenyatwa Group of Hospitals (JREC), the Medical Research Council of Zimbabwe (MRCZ) and Harare City Directorate. All participants gave informed consent. All women who had infections or conditions other than periodontal diseases such as genitourinary tract infection, concurrent antibiotic therapy, diabetes mellitus, heart disease, glomerulonephritis and those with a history of these diseases were excluded from the study. Mothers with multiple pregnancies were also excluded.

Code numbers were used to identify participants and interviews and oral assessments were conducted in private rooms. Data was collected through face to face interviews following a structured questionnaire, clinical intraoral examination and from clinical records.

A baseline questionnaire was administered to all the enrolled mothers within the immediate postpartum period ( 0 - 10 days) collecting medical, obstetric, oral health history during pregnancy and birth outcomes. Clinical intraoral examination was done by a trained nurse/midwife at enrolment. The nurse/midwife received prior training from the study dentist on how to conduct the examination. The study dentist was on standby. An inspection of the teeth and surrounding soft tissue of the oral cavity was done. Teeth were checked for plaque, missing teeth, mobility and cavities. A calibrated dental probe was used into the soft tissue sulcus around each tooth measuring the depth of the gingival crevices/periodontal pockets. Presence of any abnormalities was recorded as either present or absent. Gingival recession gingival pockets depths were measured in millimetres. Loss of attachment was computed by adding gingival recession and probing pockets depths.

The results were coded as follows: 0 if there were gingival pockets of $<3 \mathrm{~mm}$; 1) if bleeding on probing but gingiva; pockets $<3 \mathrm{~mm}$; $)$ if Periodontal pocketing $<3 \mathrm{~mm}$, but tartar present; 3 ) if there were shallow periodontal pockets 4 - 5 $\mathrm{mm}$; 4) if there was deep periodontal pockets $>6 \mathrm{~mm}$. For scores $0-2$ dental hygiene was given. Patient scoring 3 and 4 were referred to the dentist for further management.

Data was captured using research electronic data capturing (RedCap) and was analyzed using the Statistical Package for Social Sciences (SPSS). 


\section{Results}

\subsection{Demographic Data}

In this study the mean maternal age was 25.9 years SD 5.7. The participants had a mean parity of 2.3 SD 2.2, mean income of $\$ 242$ SD 213.2, mean gestational age at birth 39.7 SD 14.3 and mean pregnancy number per woman was $2.3 \mathrm{SD}$ 1.1. Of the 350 participants, $96.0 \%$ were married, single $3.5 \%$ and $0.5 \%$ divorced. About $76.3 \%$ of the participants were unemployed, $16.9 \%$ were self-employed and $6.8 \%$ employed. Regarding religion $36.7 \%$ attended Pentecostal churches, $36.3 \%$ apostolic churches while $22.7 \%$ attended the protestant churches. Majority $87.1 \%$ had attained the secondary level of education.

\subsection{Prevalence of Periodontal Disease in Pregnancy}

Overall, the prevalence of periodontal disease in the interviewed women was $48.7 \%$. Of the total sample 345 participants were available for a dental examination. However, 33.5\% reported discomfort from mouth teeth in the last 12 months. All participants had 20 or more teeth. Only $0.4 \%$ of the interviewed women had removable dentures.

Table 1 summarizes the conditions of teeth and gums. Only $47.4 \%$ participants had either good, very good or excellent condition of teeth while $82.9 \%$ had either good, very good or excellent gums.

\subsection{Tooth Care Practices}

All 350 participants were interviewed regarding tooth care. Majority (74.1\%) cleaned their teeth twice daily while $23.7 \%$ reported cleaning once a day. Majority (95.5\%) used toothbrushes while others used wooden toothpicks (27.8\%), plastic toothpicks (5.5\%), dental floss (5.8\%) and charcoal (4.3\%). Almost all (99.7\%) used toothpaste with fluoride. Three quarters (75.1\%) participants had never received professional dental care. Table 2 summarises the results on the teeth related problems faced in the current pregnancy.

\subsection{Eating Habits and Lifestyle Practices}

Regarding alcohol consumption almost everyone (99.7\%) had taken some alcohol in the current pregnancy with the majority (85.8\%) consuming 5 or more drinks per day. Table 3 summarises the foods that the participants reported eating during their last pregnancy.

\subsection{Birth Outcomes}

All the women who participated in this study had live births with $50.8 \%$ of the babies being females and $49.2 \%$ being male. Mean gestational age at birth was 38.7 weeks SD 2.5 and the mean birth weight was $3104 \mathrm{~g}$ SD 421.6. The babies had a mean length of $49.3 \mathrm{~cm}$ SD 2.3 and a mean head circumference of $34.2 \mathrm{~cm}$ SD 2.1. The mean Apgar scores at 1 minute and 5 minutes were 8.6 SD 0.3 and 9.6 SD 0.4 respectively. 


\subsection{Proportion of Neonatal Abnormalities at Birth}

About $86.1 \%$ of the babies born in the last pregnancy of the participants had no abnormalities; $2.3 \%$ had Low birth weight, $1.3 \%$ had extra digits, $0.3 \%$ had a cyst in the upper gum; 3.3\% had meconium aspiration; 2.3\% had low Apgar score; $1.7 \%$ were pre-term babies; $0.3 \%$ had short penis; $0.7 \%$ had cord around; $0.7 \%$ were macrosomic and $0.7 \%$ had deformed knee. Table 4 summarises the results on pregnancy outcomes.

Table 5 is a summary of the results on the association between periodontal disease and health outcomes. No health outcome variable was significantly associated with periodontal disease.

Table1. State of teeth and gums $(\mathrm{n}=345)$.

\begin{tabular}{ccc}
\hline Condition & Teeth (\%) & Gums (\%) \\
\hline Excellent & 7.9 & 10.4 \\
Very good & 16.5 & 47.0 \\
Good & 23.0 & 25.5 \\
Average & 32.7 & 9.0 \\
Poor & 8.3 & 1.4 \\
Very poor & 1.4 & 6.4 \\
Don't know & 10.1 & 0.3 \\
\hline
\end{tabular}

Table 2. Teeth related problems $(\mathrm{N}=350)$.

\begin{tabular}{|c|c|c|c|c|}
\hline Problem & Very often (\%) & Fairly Often (\%) & Sometimes (\%) & No $(\%)$ \\
\hline Difficulty in biting foods & 3.5 & 3.2 & 8.1 & 85.2 \\
\hline Difficulty in chewing & 6.6 & 3.2 & 10.4 & 79.7 \\
\hline $\begin{array}{l}\text { Difficulty with speech } \\
\text { pronouncing words }\end{array}$ & 1.4 & 0.6 & 2.0 & 95.9 \\
\hline Dry mouth & 0.3 & 1.2 & 7.5 & 91.0 \\
\hline $\begin{array}{l}\text { Felt embarrassed due to } \\
\text { appearance of teeth }\end{array}$ & 1.7 & 1.7 & 6.6 & 89.9 \\
\hline $\begin{array}{l}\text { Felt tense because of } \\
\text { problems with teeth/mouth }\end{array}$ & 1.2 & 2.3 & 5.7 & 90.7 \\
\hline $\begin{array}{l}\text { Having avoided smiling } \\
\text { because of teeth }\end{array}$ & 2.0 & 1.4 & 3.5 & 93.0 \\
\hline $\begin{array}{l}\text { Had a sleep that is } \\
\text { often interrupted }\end{array}$ & 2.3 & 1.7 & 10.7 & 85.2 \\
\hline Have taken days off work & 0.6 & 0.8 & 8.1 & 90.7 \\
\hline $\begin{array}{l}\text { Difficulty doing } \\
\text { usual activities }\end{array}$ & 0.9 & 2.0 & 7.5 & 89.6 \\
\hline $\begin{array}{l}\text { Felt less tolerant of spouse } \\
\text { or spouse who are to close }\end{array}$ & 0.3 & 2.3 & 5.9 & 91.4 \\
\hline $\begin{array}{l}\text { Reduced participation in } \\
\text { social activities }\end{array}$ & 0.3 & 1.3 & 5.9 & 92.4 \\
\hline
\end{tabular}


Table 3. Foods eaten during last pregnancy.

\begin{tabular}{|c|c|c|c|c|c|c|}
\hline Foods & $\begin{array}{l}\frac{\text { Several }}{\text { times }} \\
\text { a day (\%) }\end{array}$ & $\begin{array}{l}\text { Every day } \\
\underline{(\%)}\end{array}$ & $\begin{array}{l}\frac{\text { Several }}{\text { times a week }} \\
\frac{(\%)}{(\%)}\end{array}$ & $\begin{array}{l}\text { Once a } \\
\text { week (\%) }\end{array}$ & $\begin{array}{l}\frac{\text { Several }}{\text { Times a }} \\
\text { month (\%) }\end{array}$ & $\frac{\text { Never }}{\underline{(\%)}}$ \\
\hline Fresh fruit & 21.7 & 36.6 & 22.7 & 10.6 & 7.6 & 0.6 \\
\hline $\begin{array}{l}\text { Biscuits, } \\
\text { cake, cream } \\
\text { cakes }\end{array}$ & 3.6 & 4.3 & 10.2 & 22.1 & 36.0 & 23.8 \\
\hline $\begin{array}{l}\text { Sweet pies, } \\
\text { buns }\end{array}$ & 5.6 & 7.3 & 14.9 & 17.2 & 25.7 & 29.4 \\
\hline $\begin{array}{l}\text { Jam or } \\
\text { honey }\end{array}$ & 4.3 & 13.2 & 10.6 & 13.9 & 20.5 & 37.6 \\
\hline $\begin{array}{l}\text { Chewing gum } \\
\text { containing } \\
\text { sugar }\end{array}$ & 4.3 & 7.9 & 10.2 & 17.5 & 19.5 & 40.6 \\
\hline Sweets/candy & 4.3 & 5.6 & 10.2 & 18.5 & 25.4 & 36.0 \\
\hline $\begin{array}{l}\text { Lemonade, } \\
\text { coca cola or } \\
\text { other soft } \\
\text { drinks }\end{array}$ & 11.2 & 19.8 & 25.1 & 17.8 & 19.5 & 6.6 \\
\hline $\begin{array}{l}\text { Tea with } \\
\text { sugar }\end{array}$ & 19.5 & 59.4 & 9.6 & 4.0 & 2.3 & 5.3 \\
\hline $\begin{array}{l}\text { Coffee } \\
\text { with sugar }\end{array}$ & 6.6 & 13.9 & 4.6 & 7.6 & 10.6 & 56.8 \\
\hline Use snuff & 0 & 0 & 0 & 0.3 & 99.7 & Use snuff \\
\hline
\end{tabular}

Table 4. Variables for pregnancy outcomes.

\begin{tabular}{lll}
\hline Variable & Frequency & Percentage \\
\hline Gestational age & & \\
Preterm (<37 weeks) & 305 & 90.5 \\
Term babies (37 weeks and above) & 32 & 9.5 \\
Total & 337 & 100 \\
Birthweight & & \\
Normal (2500 g and above) & 330 & 93.48 \\
Low birth weight (<2500 g) & 23 & 6.52 \\
Total & 353 & 100 \\
Child Length & & \\
$<49 \mathrm{~cm}$ & 91 & 25.78 \\
Normal (49 - 51 cm) & 262 & 76.44 \\
Total & 353 & 100 \\
Child Head Circumference & & \\
$<34 \mathrm{~cm}$ & 82 & 76.44 \\
Normal & 266 & 23.56 \\
Total & 348 & 100 \\
\hline
\end{tabular}

Socio-demographic Risk Factors for Periodontal Disease: Association between Periodontal disease and health outcomes. 
Table 5. Association between Periodontal disease and health outcomes.

\begin{tabular}{lllll}
\hline Variable & $\begin{array}{l}\text { Odd } \\
\text { Ratios }\end{array}$ & $\begin{array}{l}\text { Chi square } \\
\text { value }\end{array}$ & P value & $\begin{array}{l}\text { 95\% Confidence } \\
\text { Interval }\end{array}$ \\
\hline $\begin{array}{l}\text { Gestational age } \\
\text { Term }\end{array}$ & 1 & & \\
Preterm & 0.800 & 0.342 & 0.559 & $0.386 ; 1.673$ \\
Birthweight & 1 & & & \\
$\begin{array}{l}\text { Normal } \\
\text { LBW }\end{array}$ & 0.962 & 0.008 & 0.929 & $0.412 ; 2.242$ \\
Child Length & 1 & & & \\
\hline $\begin{array}{l}\text { Normal } \\
<49 \mathrm{~cm}\end{array}$ & 1.103 & 0.163 & 0.686 & $0.684 ; 1.778$ \\
Child Head Circumference & & & & \\
$\begin{array}{l}\text { Normal } \\
<34 \mathrm{~cm}\end{array}$ & 1.111 & 0.1739 & 0.677 & $0.677 ; 1.823$ \\
\hline
\end{tabular}

\section{Factors Associated with Periodontal Disease in Pregnancy}

The association between periodontal disease and gestational age, birthweight, child health and child head circumference was not statistically significant. After adjusting for sociodemographic characteristics, the association became statistically significant. The demographic variables were: income, employment status, level of education, place of residence, age, multiple pregnancies, oral practices and frequency of dental visits.

\section{Discussion}

\subsection{Demographic Data}

The purpose of the study was to determine the prevalence of periodontal disease in pregnancy together with associated risk factors. This study aimed to determine the prevalence of and factors associated with periodontal disease and its association with pregnancy outcomes. On the prevalence of periodontal disease was $48.7 \%$, The study showed that most women complain of some problems related to their teeth in their current pregnancy. While all the women reported some sort of problems related to their teeth, almost half of the women who were interviewed reported having suffered from some form of periodontal disease during their pregnancy. Some of the problems experienced include difficulty in biting foods, chewing foods and pronouncing words. This finding supports the one carried out in maternal and child health centers in Shanghai where prevalence of periodontal disease during pregnancy was $49.6 \%$, of which gingivitis and periodontitis were the commonest complaints.

\subsection{Risk Factors for Periodontal Disease}

No significant factors were associated with periodontal disease in the current study. However other studies have reported significant risk factors for periodontal disease such as gestation age of the pregnancy and place of residence. 
Majority participants in the current study reported taking 5 or more alcoholic drinks per day in their last pregnancy. While this finding calls for health education to control alcohol consumption which has been researched on extensively and proven to have detrimental effects on the baby, there was no statistical significance on the effect of alcohol consumption on the health of the teeth of the pregnant women in the sample. This may be attributed to the high level of oral hygiene reported earlier. Several other risk factors such as tobacco smoking, poorly controlled diabetes mellitus, and cardiovascular disease have been reported in literature [9] [10] [11]. On the factors associated with periodontal disease, the Shanghai study associated the gestation of the pregnancy and place of residence with more likelihood of suffering from periodontal disease. In our study, regarding tooth care practices, the majority of women clean their teeth twice or more per day and most of them use toothbrushes. However, the majority of the respondents never received dental care from a dentist prior to their current pregnancy. Another study linked lack of knowledge of dental health to level of education and socio-economic status [12].

\subsection{Association between Periodontal Disease and Birth Outcomes}

There were no statistically significant associations between periodontal disease and birth outcomes namely birth weight and prematurity. Pregnant women with periodontal disease are at increased risk of low birth weight [13]. Screening and treatment of periodontal disease is associated with reduced preterm births and incidence of low birth weights [14]. The reduction in the incidence and prevalence of periodontal disease can reduce its associated systemic diseases and pregnancy outcomes [15]. Pregnant women with severe periodontal disease are 7.5 times more likely to go into premature labour. PD places pregnant women at greater risk for preterm birth than alcohol consumption or smoking [16].

\section{Conclusion}

No significant factors were associated with periodontal disease in the current study. However, other studies have reported significant risk factors for periodontal disease such as gestation age of the pregnancy and place of residence. Periodontal health is a relatively neglected area in perinatal care. Health care professionals should be trained in screening for periodontal disease and giving health education in order to improve oral health during pregnancy and reduce adverse perinatal outcomes.

\section{Acknowledgements}

This study was supported by a Nowergian Grant 2018.

\section{Conflicts of Interest}

The authors declare no conflicts of interest regarding the publication of this paper. 


\section{References}

[1] Srinivas, S.K. and Parry, S. (2012) Periodontal Disease and Pregnancy Outcomes: Time to Move on? Journal of Women's Health, 21, 121-125. https://doi.org/10.1089/jwh.2011.3023

[2] Corbella, S., Taschieri, S., Francetti, L., De Siena, F. and Del Fabbro, M. (2012) Periodontal Disease as a Risk Factor for Adverse Pregnancy Outcomes: A Systematic Review and Meta-Analysis of Case-Control Studies. Odontology, 100, 232-240. https://doi.org/10.1007/s10266-011-0036-Z

[3] Morsani, J.M., Aminoshariae, A., Han, Y.W., Montagnese, T.A. and Mickel, A. (2011) Genetic Predisposition to Persistent Apical Periodontitis. Journal of Endodontics, 37, 455-459. https://doi.org/10.1016/j.joen.2011.01.009

[4] Katz, J. and Bimstein, E. (2010) Periodontal Disease and Obesity in Children. The Israel Medical Association Journal, 12, 775.

[5] Chalmers, N.I., Oh, K., Hughes, C.V., Pradhan, N., Kanasi, E., Ehrlich, Y., et al. (2015) Pulp and Plaque Microbiotas of Children with Severe Early Childhood Caries. Journal of Oral Microbiology, 7, 25951. https://doi.org/10.3402/jom.v7.25951

[6] Suri, V., Rao, N.C. and Aggarwal, N. (2014) A Study of Obstetricians' Knowledge, Attitudes and Practices in Oral Health and Pregnancy. Education for Health, 27, 51. https://doi.org/10.4103/1357-6283.134313

[7] Hashim, R. and Akbar, M. (2014) Gynecologists' Knowledge and Attitudes Regarding Oral Health and Periodontal Disease Leading to Adverse Pregnancy Outcomes. Journal of International Society of Preventive and Community Dentistry, 4, S166. https://doi.org/10.4103/2231-0762.149028

[8] Brar, P. (2015) The Effectiveness of Education Based Programs Delivered by Nondental Professionals for Preventing Early Childhood Caries. PhD Thesis, Faculty of Graduate Studies, University of Calgary.

[9] Johnson, G.K. and Slach, N.A. (2001) Impact of Tobacco Use on Periodontal Status. Journal of Dental Education, 65, 313-321.

[10] AlJehani, Y.A. (2014) Risk Factors of Periodontal Disease: Review of the Literature. International Journal of Dentistry, 2014, Article ID: 182513. https://doi.org/10.1155/2014/182513

[11] Pihlstrom, B.L., Michalowicz, B.S. and Johnson, N.W. (2005) Periodontal Diseases. The Lancet, 366, 1809-1820. https://doi.org/10.1016/S0140-6736(05)67728-8

[12] Thomas, N., Middleton, P. and Crowther, C. (2008) Oral and Dental Health Care Practices in Pregnant Women in Australia: A Postnatal Survey. BMC Pregnancy and Childbirth, 8, 13. https://doi.org/10.1186/1471-2393-8-13

[13] López, N.J., Smith, P.C. and Gutierrez, J. (2002) Higher Risk of Preterm Birth and Low Birth Weight in Women with Periodontal Disease. Journal of Dental Research, 81, 58-63. https://doi.org/10.1177/002203450208100113

[14] Polyzos, N.P., Polyzos, I.P., Mauri, D., Tzioras, S., Tsappi, M., Cortinovis, I., et al. (2009) Effect of Periodontal Disease Treatment during Pregnancy on Preterm Birth Incidence: A Metaanalysis of Randomized Trials. American Journal of Obstetrics \& Gynecology, 200, 225-232. https://doi.org/10.1016/j.ajog.2008.09.020

[15] Nazir, M.A. (2017) Prevalence of Periodontal Disease, Its Association with Systemic Diseases and Prevention. International Journal of Health Sciences, 11, 72.

[16] Offenbacher, S., Lin, D., Strauss, R., McKaig, R., Irving, J., Barros, S.P., et al. (2006) Effects of Periodontal Therapy during Pregnancy on Periodontal Status, Biologic Parameters, and Pregnancy Outcomes: A Pilot Study. Journal of Periodontology, 77, 2011-2024. https://doi.org/10.1902/jop.2006.060047 